\title{
Allusion as a feature of intertextuality in newspapers and publicistic discourses
}

\author{
Juliya Nikitina ${ }^{1, *}$, Oksana Lebedinskaya ${ }^{1}$, and Olga Plakhova $^{1}$ \\ ${ }^{1}$ Togliatti State University, 45020, 14 Belorusskay str., Togliatti, Russia
}

\begin{abstract}
Discourse studies, being quite extensive in recent decades, remain more focused on literary genres (poems, short stories, novels), which are subject to consideration as pragmalinguistics and sociolinguistics for a particular recipe ideas typical situation. Meanwhile, newspapers and publicistic discourse can be considered a vast field for research, both from the point of view of text structures, its content and formal features, not the least of which are the figures of speech, in particular, allusion. The variety of types of allusions in newspaper and magazine texts and their titles gives them the richness, emotion and angst. This article discusses the text - discourse distinguishing; intertextuality and its features; peculiarities of functioning of the allusions in the headlines of newspaper and magazine articles in English. Also, the article provides statistical data on the frequency of allusions to the most vivid thematic groups such as culture, sports, economics and politics. Being a very interesting element of intertextuality, allusion has its potential in the process of formation of skills of all types of speech activity.
\end{abstract}

\section{Introduction}

The media (newspapers, magazines, Internet correspondence, radio, television) is designed to acquaint readers, listeners, viewers with what is happening in the world. It is logical that they are the rapidly changing and constantly evolving field, both from the point of view of the content (including languages and the form, reflecting the changes in mass-information discourse associated with the social environment and politics. That is why, newspaper and magazine articles, texts of radio and television have invaluable potential for the analysis of the language change and the formation of skills and abilities of all types of speech activity: reading, listening, writing and speaking.

\section{Allusion as a feature of intertextuality}

\subsection{Newspaper and publicistic discourses}

\footnotetext{
* Corresponding author: julia-722598@ yandex.ru
} 
The definition of "newspaper and publicistic discourses", as well as the term "discourse", itself continues to be debated by researchers and linguists. The emergence of the concept of "discourse" is associated with the name of Z. Harris, the American scientist-structuralist who introduced the term in 1952 [1].

As a synthesis of different authors' interpretations, the discursive terminology is found in the work "Theory and practice of discourse" by P. Serio. "Discourse" is shown as: 1) an equivalent to the concept of "speech" (F. Saussure), 2) a unit size superior to that of a phrase, 3) the impact of the statements on its recipients taking into account the situation of the utterance, 4) a conversation as the main type of speech, 5) a speech from the position of the speaker as opposed to a narrative, which does not account for such a position (for E. Benveniste), 6) the usage of language units, their speech actualization, 7) socially or ideologically restricted type of expressions, for example, feminist discourse, 8) a theoretical construct designed to research the conditions of production of the text [2, pp. 14-53].

Another interpretation is proposed by B. M. Gasparov, who considers discourse as a linguistic coexistence, in which it is necessary to consider the communicative intentions of the author, the relationship of the author and recipients, various significant and accidental circumstances, genre and stylistic features, as the communication and the communicative situation in which it is included, a lot of associations with previous experiences [3, pp. 251259].

If to speak about newspaper-publicistic discourse or style, it has a number of aspects that define it: 1) the functional aspect performs: a) informative functions, b) the formation of public opinion, c) entertaining functions; 2) the taxonomic aspect divides a newspaperpublicistic discourse into the macrosystem (the language of mass communication) and the microsystem (the language of newspaper and magazine publications, radio programs, television programs); 3) the referential aspect speaks that mass media are designed to the general public and highlight all areas of activities (culture, politics, health); 4) the communicative aspect differentiates newspapers on quality and mass, and professionally oriented newspapers; 5) the linguistic aspect involves such concepts as simplicity of presentation, brevity and expressiveness, background knowledge; 6) the pragmatic aspect encompasses the evaluation, directivity, visual agitation and propaganda. The main characteristics of microsystems of newspapers are brief news stories, news articles, editorials, analytical articles, comments, materials pertaining to the fields of business, scientific and technical information, sports information, reviews (book, theatre, movies, obituaries, advertising [4, pp. 224-236].

The basic communicative intentions of authors of mass-information (newspaperpublicistic) discourse are information and influencing ones, that is obvious. Both functions vividly manifest themselves in headlines. Taking into account that a headline (a title of an article) is a part (a substyle) of the newspaper functional style, so it is a part of the newspaper discourse. The opinion of V. E. Chernyavskaya confirms the given view by allocating in the structure of a newspaper text four obligatory structural and compositional components: a title, an introduction, a main part and a conclusion [5, p. 42].

The first two of the components mentioned above (a title and an introductory part) carry the most important communicative burden. Due to their close logical-semantic connection, the title and the introductory part can be considered as a single introductory unit, which attracts the most attention of readers [6, pp. 356-367]. The variety of stylistic, intertextual elements used by the authors help them.

\subsection{Intertextuality and its features}


Intertextual elements are those which could be sited within the intertextual theory. Most scientists agree that "dealing with intertextuality, it is quite normal to start with Kristeva ... with reference to what Bakhtin calls the dialogic aspect of language" [7, pp. 56-57].

There are many interpretations of the term "intertextuality" [8, pp. 54-61], but at its essence intertextuality is either the "absorption or transformation of another text" $[9, \mathrm{p}$. 146], and it is connected with either the mixture of statements and texts, or the derivation of one text from another" [10, p. 322].

In an attempt to distinguish the term "intertextuality" in his work "Intertextuality: the categorical apparatus and typology”, V. P. Moskvin writes: “...many authors understand intertextuality as a literary device, as trope or a stylistic figure, a method for construction of a literary text; however, intertextuality is not a reception, and the associative base for methods of citation of an application, allusion, paraphrase and other shapes of the intertext, which do not always become ambiguous, and therefore neither one of the interpretations of the path are incompatible" [8, p. 54].

There are various forms and methods to include intertextual elements in journalistic and literary contexture, for example, text reminiscences [11, pp. 252-260], which include quasipositive [12, pp. 44-49], quasiunitary [13, pp. 167-168], a paraphrase, which, in turn, can be considered an allusion [14, pp. 63-70].

\subsection{Allusion as an element of intertextuality}

So an allusion is understood as one of the mostly frequently used intertextual element.

The Oxford dictionary notes the following meaning of the term allusion: 1) language play, word play, pun; 2) symbolic use or comparison; metaphor, allegory; 3) covert, implied or indirect meaning; occasional or of secondary importance [15, p. 349]. This interpretation leads to unwanted encounters allusions to the metaphor, allegory, trope, paronomasia, pun, alliteration [16, p. 42].

Many Russian linguists consider an allusion as a stylistic figure that contains either a citation, or a reference to a literary, historical, mythological, religious or political situation, a fact, a person, fixed in written sources or in conversational speech.

Any piece of intertext, in particular an allusion can rely either on: 1) preceding in relation to the perceived so called "left" text, or 2) other text, i.e. pre-text [8].

According to I. S. Khristenko, an allusion is a type of parody which does not imply the stylistic means of the original source and does not seek for destroying the aesthetic value of the works parodied; it is a paraphrase of the text, which sets out the initial "high" the text "low" style [17, p. 43].

A slightly different interpretation is proposed by B. M. Gasparov, according to whom allusion is borrowing only certain elements of the pretext, and the whole statement or string pretext, correlated with the new text, present in the last implicit [3, p. 39].

Thus, to understand allusively text, the recipient needs to have certain background knowledge. In background knowledge of the addressee should include knowledge about the main signs of allusion; otherwise, he will not be able to achieve adequate decoding. In this regard, J. Genet says about the two types of the addressee: the addressee for whom an allusive aspect of the text has a zero value and the addressee for which pretext is a significant precedent [18, pp. 216-217].

\subsection{Sources of allusions}

As pointed out by E.V. Grudeva, the headlines and the texts themselves use a wide variety of literary allusions: 1) literature citations-reministsentsii, titles of works, names of characters, 2) modified statements of scientists, politicians, cultural figures, 3) Sola 
Scriptura (facts, names, phrases from the old and New Testament) and the stories and characters of myths, 4) quotes, including transformed, from popular songs, 5) to paraphrase the name of television and movies, phrases from popular movies and television programs, advertising, 6) the transformed expression, 7) titles of paintings, sculptures and other works of art [19, pp. 134-143].

Here are some literary allusions in the headline and texts of newspapers and magazines.

A Man Without Mask (The Guardian, 2006, no. 5): the allusion to the name of A. Dumas's famous novel A Man in Iron Mask;

Mysteries of Trade Diplomacy (Business Week, 2006-07-31): the allusion to the comedy by Eugene Scribe Secrets of the Madrid Court;

Around the World in 80 Flavors (The Times, 2006, no. 23): the allusion to Jules Verne Around the world in 80 days;

Rich man, poor man (The Times, 2015-10-10): the pure allusion to the 1970 year novel by Irwin Shaw, an American writer;

The Founder of Robinhood Wants You to Trade Stocks for Free (Businessweek, 201606-04): a transformed allusion to Robin Hood, a legendary hero of the English folklore.

But the leader, and it is rather clear, remain works by William Shakespeare, especially his most staged tragedy Hamlet:

To treat or not to treat (The Sunday Telegraph, 2003, no. 12);

To test or NOD-2 test: what is the question? (Forbes, 2003-05-05);

To be or not to be Hamlet: who was great, who was't (The Times, 2015-10-10) and many others.

Rather often biblical and mythological allusions can be found in the headlines and articles:

In the Fed we Trust (The Times, 2004, no. 3) compare to In God we Trust;

Anthony Martial is Facing a Baptism of Fire at Manchester Unite (The Telegraph, 2015-10-10) is a reference to a phrase originating from the words of John the Baptist in Matthew 3:11;

Arthur Andersen Rises From The Ashes (The Times, 2015-10-10): a reference to Phoenix, a mythical bird from Greek and Roman legends;

China the Promised Land for South African Wine Makers (Reuters - Life, 2016-05-25): South African wine technologies are sold to China as something precious and promised as Israel's land was promised to Abraham, Isaac, and Jacob by God.

Also, in newspapers and magazines, a lot of allusions to different phenomena in the cultural sphere can be used by journalists (historical events, famous people, music works, movies, etc.).

Hannah Betts in the article No, please, not "babe" writes: A terrible thing has befallen the House of Windsor - worse than Fergie, Andrew or any mere annus horribilis (The Times, 2016-05-26). Annus horribilis is a reference to the Queen's words about the horrible events in 1992;

We will schlock you (The Daily Telegraph, 2003, no. 24) is a periphrasis name of the famous song We will rock you by the British rock band "Queen," emphasised by the barbarism;

Life After Love Locks: Art Comes Back to Paris' Pont des Arts Bridge (Newsweek, 2016-05-28): journalist Tufayel Ahmed tells about "a new era for Paris' Pont des Arts bridge, once known as "love lock bridge" and uses, likely unconsciously, an allusion to a song Do you believe in life after love? by Sher;

His Art Will Go On! Or Will It Soon Be 'Leo Who'? (Newsweek, 1998-12-07): contains comments on Leonardo DeCaprio's career and alludes to the film Titanic which he stared in and where Celine Dion performed the song My heart will go on; 
Interiors: Seven Magnificent Garden Updates (The Telegraph, 2015-10-10): an allusion to a 1960 western film The Magnificent Seven directed by John Sturges and starring Yul Brynner;

The Empires Strike Back (Businessweek, 2016-05-19): the article tells about two enterprise giants Oracle and SAP which have redefined their core strategies to focus on the cloud and dedicated most of their acquisition budgets to cloud-based companies. The headline has an allusion to a 1980 adventure, action, fantasy film Star Wars: Episode VThe Empire Strikes Back directed by I. Kershner;

The D Word: Will Finally Admitting She is Angry Help? (The Telegraph, 2015-10-10) tells about a divorce. The word starts with the letter "d". The allusion refers to $D$-day when alien troops landed in Normandy in 1944 and opened the second front;

China Risks 'Great Wall of Self-Isolation,' Says U.S. (Businessweek, 2016-06-04): U.S. Defense Secretary Ash Carter comments China`s actions at the global defense forum in Singapore. The headline has an allusion to the name of a world famous Chinese sightseeing - The Great Wall, which was built to protect China from anomies;

Hong Kong Marks Tiananmen Amid Tension Over China's Influence (Businessweek, 2016-06-04): the article alludes to the event that happened almost three decades ago on China's Tiananmen Square where there was a crackdown on pro-democracy students' demonstration during which a lot of unarmed people were killed.

Apart from the mentioned sources of allusions transformed clichés, proverbs and saying can be named. Compare:

Bad News Is Good News (Financial Times, 2004-06-01) - No News Is Good New;

Out Of The Limelight (The Daily Telegraph, 2005, no. 3) - To Be In The Limelight;

Marriage Made In Barrels (The Guardian, 2003, no.28) - Marriage Made In Heavens.

\subsection{Functions of allusions}

Researchers distinguish different types of intertexual elements: quotations, reminiscences, allusions, etc. Each of them have their own functions in the texts, groups, sources, topics in which they are mostly used. For instance, M. V. Sablina, focusing on two main functions of allusion, emotional-evaluative and associative, states that "the allusion is often used as periphrasis" [20. P. 46-48]. Let's examine some examples.

In the article Royal Feud! How Camilla Secretly Schemed To Sabotage Queen-To-Be Kate, which is a review on the book about the relationship between members of the British royal family, we find:

Fifteen years of feuding! The Duchess of Cornwall, otherwise known as Camilla Parker Bowles, has despised Prince Williams' stunning wife, Duchess of Cambridge Kate Middleton, since she first laid eyes on her, royal biographer Christopher Andersen writes in his scandalous new tell-all, Game of Crowns. (Radar, 2016-05-30).

It is obvious that the highlighted phrase is an allusion based on the name of a very famous series Game of Thrones and formed as an analogy to it, so the function is associative one.

Here is one more example of the associative function of the allusion. In the article The Founder of Robinhood Wants You to Trade Stocks for Free (Businessweek, 2016-06-04), there is a passage:

In 2011, Baiju Bhatt and Vladimir Tenev, both Stanford physics graduates, were living in New York, building trading systems for large institutional investors and hedge funds. After Occupy Wall Street, they decided to apply their expertise to improve access to the financial-services industry for young people. In 2013 they founded Robinhood, a commission-free trading app. Robinhood is now the fastest-growing brokerage, with more 
than $\$ 3$ billion in trading volumes. Its almost 1 million customers have saved some $\$ 70$ million in trading commissions.

On the site of the movement Occupy Wall Street, we can read that it is a peoplepowered movement that began on September 17, 2011 in Liberty Square in Manhattan's Financial District, and fights back against the corrosive power of major banks and multinational corporations over the democratic process, and the role of Wall Street in creating an economic collapse that has caused the greatest recession in generations [21].

As for Robin Hood, everybody knows he was an English legendary hero who tried to help poor people giving them money which he stole from the rich.

Andrew Morton starts the article A life in her shadow with the sentence: It was New Year's 1992 - the year the queen would late call her annus horribilis - and the House of Windsor was crumbling into Ruritanian farce and fantasy.

The phrase annus horribilis was formed as an analogy to the Latin phrase annus mirabilis which means "wonderful year" or "year of miracles". It is the title of a poem composed by English poet John Dryden about the events of 1666. According to the Oxford English Dictionary "the year was beset by great calamity for England (including the Great Fire of London), but Dryden chose to interpret the absence of greater disaster as miraculous intervention by God, as "666" is the Number of the Beast and the year 1666 was expected by some to be particularly disastrous". Also, there were some scientific inventions, great works of literature, and the English fleet defeated a Dutch fleet.

On the contrary, annus horribilis means "horrible year". The Queen invented and used this phrase herself describing the year of 1992: "1992 is not a year on which I shall look back with undiluted pleasure", because this the third year of her Majesty children (Prince Charles, Princess Anne, and Prince Andrew separated their spouses; Diana, Princess of Wales's published a tell-all biography describing her unhappy marriage to Charles; The Mirror published transcripts of calls between Prince Charles and Camilla Parker-Bowles, with whom he was having an affair). The Queen was rather emotional in her evaluation, so the function of the allusion is emotional-evaluative.

On the $3 \mathrm{~d}$ of June 2016 Muhammad Ali, a world famous boxer, died. There were published a lot of articles in newspapers and magazines about his life and career. Many authors cited his words: Float like a Butterfly, Sting like a Bee.

For example, in Like a butterfly: Obituary: Muhammad Ali died on June 3rd aged 74 (The Economist, 2016-06-04) this phrase is alluded in the headline. It refers to his style of boxing and has an associative function.

In the same article we can read further: "The most popular fight since Hitler and Stalin-180m Americans rooting for a double knockout" about Cassius Clay's (Muhammad Ali`s) fighting against Sonny Liston for the world heavyweight boxing championship which he won. Hitler and Stalin were leaders of rivaling armies during the World War II. The Soviet Union headed by Stalin won. Here the function of the allusion is associative and evaluative.

\section{Statistical data}

The empirical analysis of about 150 titles of newspaper and magazine articles and from American and British sources shows that about $30 \%$ of them contain biblical, mythological, literary or historical allusions. Most often, authors resort to allusions in the headlines of the cultural subjects, and it happens less often in articles on sports, which is not surprising. In addition it should be noted that pure allusion, direct quotation is rarely used. Often, authors resort to various lexical and grammatical transformations, needed for a more vivid transmission of the article in the header. 
Among 125 articles, only 11 allusions were found. The main sources of allusion in them remain proper names.

In the Table 1, the results of the research are given. The sources of allusions are presented, as well as the mostly used topics.

Table 1. Sources of allusion.

\begin{tabular}{|c|c|c|c|c|c|c|c|c|}
\hline \multirow[t]{3}{*}{ Topic } & \multicolumn{8}{|c|}{ Sources of allusion } \\
\hline & \multicolumn{2}{|c|}{ Names } & \multicolumn{2}{|c|}{ Bible, myths } & \multicolumn{2}{|c|}{$\begin{array}{c}\text { Current and } \\
\text { historical events }\end{array}$} & \multicolumn{2}{|c|}{$\begin{array}{l}\text { Literature, } \\
\text { music, films }\end{array}$} \\
\hline & $\begin{array}{l}\stackrel{\mathscr{\Xi}}{\Xi} \\
\stackrel{\Xi}{\Xi} \\
\stackrel{\Xi}{\Xi} \\
\Xi\end{array}$ & 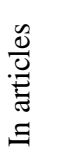 & $\begin{array}{l}\stackrel{\Xi}{\Xi} \\
\stackrel{\Xi}{\Xi} \\
\stackrel{\Xi}{\Xi} \\
\Xi\end{array}$ & 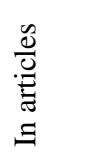 & $\begin{array}{l}\stackrel{\mathscr{U}}{\Xi} \\
\stackrel{\Xi}{\Xi} \\
\stackrel{\Xi}{\Xi} \\
\Xi\end{array}$ & 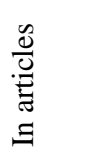 & $\begin{array}{l}\stackrel{\mathscr{U}}{\Xi} \\
\stackrel{\Xi}{\Xi} \\
\stackrel{\Xi}{\Xi} \\
\Xi\end{array}$ & $\begin{array}{l}\frac{\mathscr{U}}{0} \\
\stackrel{\Xi}{\Xi} \\
\Xi\end{array}$ \\
\hline Culture & $38,6 \%$ & $3,2 \%$ & $2,2 \%$ & - & $2,2 \%$ & - & $34 \%$ & - \\
\hline Sports & - & - & - & $0,8 \%$ & $4,5 \%$ & - & $4,5 \%$ & - \\
\hline Politics & - & - & $2,2 \%$ & $0,8 \%$ & $4,5 \%$ & $2,4 \%$ & $20,5 \%$ & - \\
\hline Economics & - & $1,6 \%$ & $4,5 \%$ & - & $4,5 \%$ & - & $15,9 \%$ & - \\
\hline
\end{tabular}

According to the statistics, the frequency of the usage of allusions in headlines of the articles on cultural, political and economic subjects is higher than in the headlines of the articles on sports. The use of names of characters and famous people in the quality of allusion is prevalent in nature, as it is better perceived by readers of all walks of life. Allusions to biblical stories and events can really be intended for a limited circle of people.

\section{Conclusion}

In conclusion, we may say that: (a) being a vivid element of intertexuality, an allusion has different sources, highlighting all areas of activities (culture, politics, health); (b) being a part of newspaper-publicistic discourse, it can be found in brief news stories, news articles, editorials, analytical articles, comments, obituaries and has a number of functions including the formation of public opinion; (c) linguistically, it can belong to different types; (d) the above mentioned features of allusions have their manifestations in lingua-didactics or methods of teaching English and the formation of skills of all types of speech activity (reading, listening, speaking and writing) [22, pp. 23-26.].

\section{References}

1. Z. Harris, Discourse analysis (http://waucondastore.com/discourse-analysis-zharris, 2012)

2. P. Serio, Theory and practice of discourse (Moscow, Oxford, 2000)

3. B. M. Gasparov, Language, memory, image: linguistics of language existence (New literary review, Moscow, 1996)

4. I. R. Galperin, Stylistics of the English language (Moscow, 1981)

5. V. E. Chernyavskaya, Intertextual interaction as a basis of scientific communication (St. Petersburg, 1999)

6. I. D. Arutyunova, Izv. of the USSR Acad. of Sc. Se. of lit. and lan, 4 (1981) 
7. Haberer, Lit, 49,5 (2007)

8. V. P. Moskvin, Prob. of intertex (2013)

9. J. Kristeva, Recherches pour une semanalyse (1969)

10. J. Jasinski, Sourcebook on rhetoric (2001)

11. N. D. Burvikova, Works of IX Con. of MAP. Brat.: pap. and rep. of Rus. sc. (1999)

12. V. B. Krivenko, Rus. Rech, 3 (1993)

13. E. A. Zemskaya, Poet. Styl. Lan. and cul.: the mem. of T. G. Vinokur (1996)

14. V. P. Moskvin, Phil. Sc., 1 (2002)

15. The Oxford English Dictionary (1989)

16. V. P. Moskvin, Russkaya rech. (http://russkayarech.ru/files/issues/2014/1/ Moskvin\%2037-43.pdf, 2014)

17. S. Khristenko, Phil. 9 (1992)

18. J. Genet, St. and sig. (1998)

19. E. Grudeva, Rus. lan.: His. and mod. st. (1999)

20. M. V. Sablina, Mir Rus. Sl, 4 (2009)

21. The Occupy Wall Street movement (http://occupywallst.org/about/)

22. Y. A. Nikitina, Bal. Gum. Zh, 3 (12) (2015) 